\title{
Density of Somatic Innervation on Mammalian Autonomic Ganglion Cells Is Inversely Related to Dendritic Complexity and Preganglionic Convergence ${ }^{1}$
}

\author{
CYNTHIA J. FOREHAND² \\ Department of Physiology and Biophysics, Washington University School of Medicine, St. Louis, Missouri 63110
}

\begin{abstract}
I have studied superior cervical ganglion cells in mouse, hamster, rat, guinea pig, and rabbit by electron microscopy to determine how the distribution of synapses on these neurons is affected by the systematic differences in dendritic morphology and preganglionic convergence that are evident in the superior cervical ganglia of these species (Purves, D., and J. W. Lichtman (1985) Science 228: 298-302). The density of dendritic innervation is approximately the same in these animals regardless of target cell geometry (and always greater than the density of synapses on the cell soma); however, more complex ganglion cells, which are innervated by commensurately more axons, receive progressively fewer cell body synapses than geometrically simpler ganglion cells. Evidently the somatic membrane becomes a less favorable site for synapse formation as dendritic complexity and the number of inputs increase. This paradoxical decrease in the density of somatic innervation as preganglionic convergence increases may reflect competitive interactions between the axons innervating individual ganglion cells.
\end{abstract}

The mechanisms that determine the allotment of synapses to dilferent regions of postsynaptic neurons are important because neuronal function depends on the specific arrangement of synapses on individual cells. For example, the number and distribution of synapses on a neuron are major determinants of its integrative ability. Mammalian sympathetic ganglia provide a simple context in which to explore these aspects of neuronal innervation.

Synapses on neuronal cell bodies are relatively rare in mammalian sympathetic chain ganglia, although they are common in mammalian parasympathetic ganglia and in some lower vertebrate sympathetic ganglia (Szentágothai, 1964; Matthews, 1983; but see Yokota and Yamauchi, 1974). Parasympathetic ganglion cells that receive numerous somatic contacts, such as rat submandibular ganglion cells, are geometricaliy simple and are innervated by only one or two

Received March.11, 1985; Revised May 6, 1985;

Accopted May 6, 1985

\footnotetext{
'This work was supported by National institutes of Health Grants NS 18629 and 11699 (to D. Purves) and was carried out during the tenure of a postdoctoral fellowship from the Muscular Dystrophy Association. Excellent technical assistance was provided by P. Newton and D. Dill. I thank Dr. D. Purves for support and advice during the course of this project. R. Hadley, J. Lichtman, E. Rubin, J. Sanes, W. Snider, and J. Voyvodic provided useful comments on the manuscript.

${ }^{2}$ Present address: Department of Anatomy and Neurobiology, Washington University School of Medicine, 660 South Euclid Avenue, St. Louis, MO 63110 .
}

preganglionic axons (Lichtman, 1977). Conversely, ganglion cells with fow somatic contacts, such as rat supcrior corvical ganglion cells (Smolen and Raisman, 1980), are geometrically complex and are innervated by a number of different preganglionic axons (Purves and Lichtman, 1985). These observations in different regions of the autonomic nervous system suggest that the density of synapses on somatic membrane may be inversely related to the dendritic complexity of the postsynaptic neuron and to the number of preganglionic axons that converge upon it (see also Yokota and Burnstock, 1983). I have explored this issue directly by examining the innervation of superior cervical ganglion cells in the mouse, hamster, rat, guinea pig, and rabbit where both dendritic complexity and the number of preganglionic inputs increase systematically with increasing animal size (Purves and Lichtman, 1985). The results show that the density of somatic innervation is inversely proportional to the dendritic complexity of these neurons and to the number of different inputs that they receive. Some of these results have been reported in abstract form (Purves et al., 1984).

\section{Materials and Methods}

Tissue preparation. Young adult mice (20 to $30 \mathrm{gm})$, hamsters (70 to 140 $\mathrm{gm})$, rats (150 to $200 \mathrm{gm})$, guinea pigs $(270$ to $450 \mathrm{gm}$ ), and rabbits (900 to $1800 \mathrm{gm}$ ) were anesthetized with pentobarbitol and perfused through the heart with $0.9 \% \mathrm{NaCl}$ followed by a mixed-aldehyde fixative ( $2 \%$ paraformaldehyde, $2 \%$ glutaraldehyde, $4 \%$ sucrose in $0.1 \mathrm{M}$ phosphate buffer, $\mathrm{pH}$ 7.3). The superior cervical ganglia were removed and kept overnight in the same fixative at $4{ }^{\circ} \mathrm{C}$. Ganglia were then rinsed in $0.1 \mathrm{M}$ phosphate buffer conlaining $5 \%$ sucrose and postfixed in $1 \%$ osmium lelroxide in phosphate buffer for $2 \mathrm{hr}$. Ganglia were dehydrated in acetone and embedded in Araldite.

The right superior cervical ganglion of three animals of each species was sectioned in the transverse plane; the contralateral ganglion from one animal of each species was sectioned in the horizontal plane. Thin sections $(\sim 0.1$ $\mu \mathrm{m})$ were obtained from four different levels of each ganglion; at each level, sections were collected on Formvar-coated slot grids for analysis of somatic or dendritic innervation and on uncoated 200 mesh grids (Pelco) for analysis of the density and distribution of synapses within the ganglion. All sections were stained with lead citrate and uranyl acetate and examined by electron microscopy.

Data collection and analysis. The density of somatic innervation was determined from the sections collected on the slot grids by scanning the perimeters of 30 to 50 cell body profiles from each of four ganglionic levels at a magnification of $\times 8000$. Only principal cell profiles containing at least one nucleus with a nucleolus were examined. The number of somatic synapses was recorded and a photograph was taken of every 10th cell at a magnification of $\times 2500$ in order to measure the average circumference of the somata. In order to be counted, a synaptic profile had to have a distinct cluster of presynaptic vesicles opposite a postsynaptic density (see Fig. 1). Although some small percentage of the synapses in the ganglion may derive from ganglion cell collaterals or ganglionic interneurons (see Matthews, 1983), no attempt was made to count these separately. 

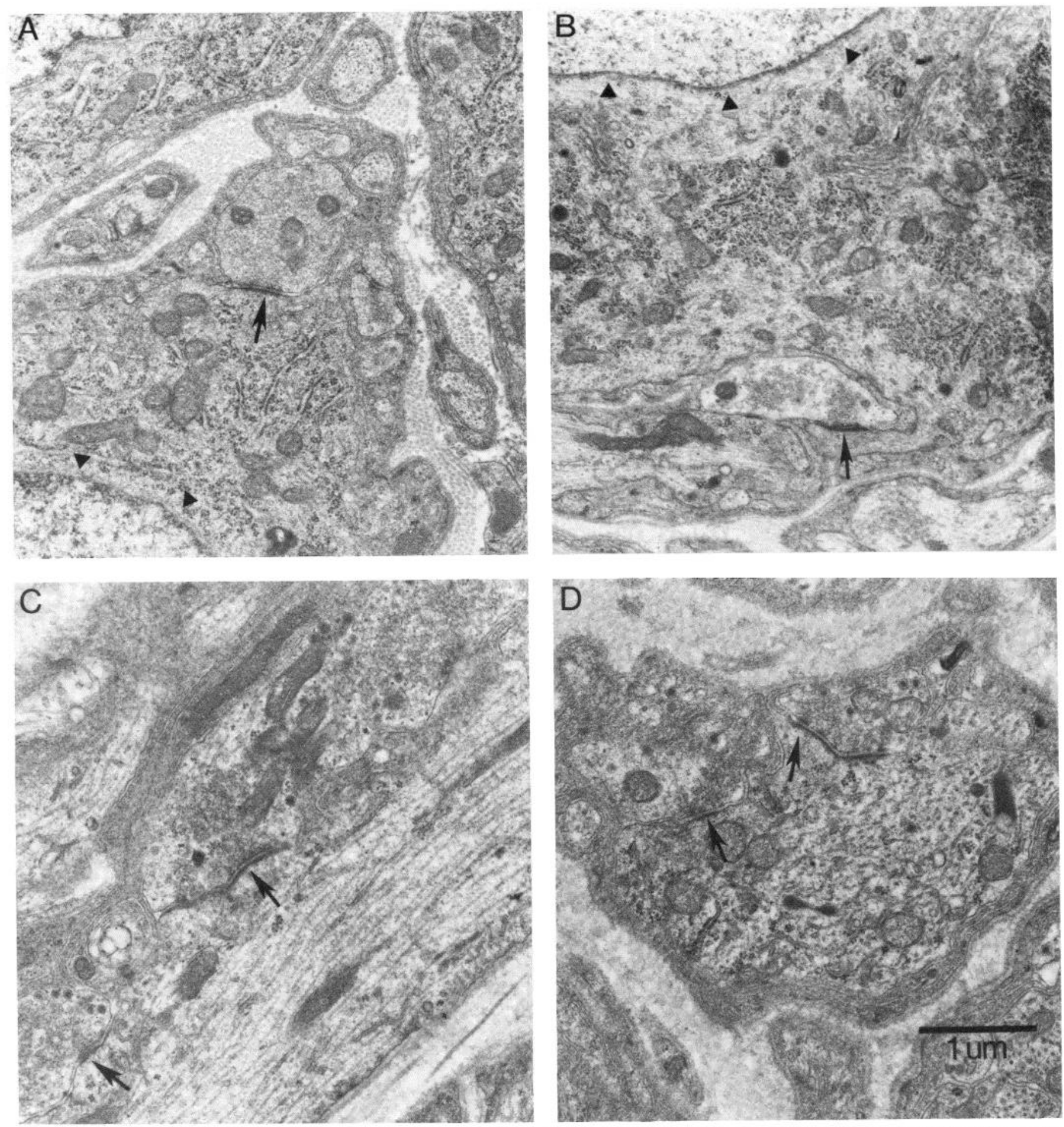

Figure 1. Examples of synapses on superior cervical ganglion cells. Cell body synapses on mouse $(A)$, and rat $(B)$ neurons and dendritic synapses on longitudinal $(C)$ and transverse $(D)$ sections of rabbit dendrites are shown. Arrows indicate synapses; arrowheads indicate ganglion cell nuclei. The calibration bar applies to all panels.

The density of innervation on dendrites in the various species was determined from the horizontal sections through the ganglia to take advantage of the fact that the dendrites tend to be oriented in the long axis of the ganglion. Ten photographs of dendrites from randomly selected areas of each of four levels were taken at a primary magnification of $\times 5000$. The total length of dendritic membrane and the number of synapses present on the dendritic profiles were determined from these photographs.

The overall density of ganglionic synapses and the percentage of syn apses on ganglion cell somata and dendrites were determined from the sections collected on mesh grids. Three to five grid squares $\left(8,100 \mu \mathrm{m}^{2}\right.$ each) from four levels of each ganglion were scanned at a magnification of $\times 8,000$ and the total number of synapses and their occurrence on cell somata or dendrites were recorded. At least three synapses from each grid square were photographed at $\times 10,000$ in order to compare active zone size in the various species; all nucleated cell profiles that contained a nucleolus and were completely within a grid square were photographed at $\times 2,500$ for comparison of ganglion cell size.

Measurements of cell circumference, dendritic length, and length of 
synaptic membrane were made from the photomicrographs using a digitizing tablet linked to a PDP-11/44 computer (a general purpose graphics language was supplied by J. Voyvodic).

\section{Results}

General observations. Synaptic ultrastructure (Fig. 1) was similar among the five species examined; detailed descriptions of synapses on superior cervical ganglion cells are given elsewhere (e.g., Matthews, 1974, 1983). The overall density of synapscs within the ganglion was also similar from animal to animal (Table I). However, the apportionment of synapses in the ganglion onto cell bodies or dendrites varied according to species. In the mouse superior cervical ganglion $8.5 \%$ of all synapses are found on somatic membrane, whereas in the rabbit, somatic synapses comprise only $0.8 \%$ of the total; the other species showed intermediate values (Table I). These numbers compare the relative distribution of synapses within the ganglia and do not indicate the absolute density of cell body or dendritic innervation. To assess actual synaptic densities, the numbers of synapses per unit length of postsynaptic membrane were determined (see below).

Synapses on ganglion cell somata. The number of synapses per unit length of somatic membrane decreased across these species in the order: mouse, hamster, rat, guinea pig, and rabbit (Fig. 2A). Thus, the number of synapses per $1000 \mu \mathrm{m}$ of somatic membrane in the mouse is nearly 6 times greater than in the rabbit, about 4fold greater than in guinea pig, and 2-fold greater in mouse than in rat or hamster. The order of decreasing density of cell body synapses across species is the same as that observed for increasing ganglion cell complexity and increasing preganglionic convergence onto ganglion cells (Fig. 2B; Purves and Lichtman, 1985). The diminished density of somatic synapses on more complex ganglion cells does not reflect a general decrease in ganglionic synapses in different species since the average overall density of synapses within each superior cervical ganglion is similar (see Table I).

Estimates of the total number of synapses on the somatic surface of typical superior cervical ganglion celis in each species indicate that this value also decreases with increased dendritic complexity and convergence (Table I; cf. Fig. 2B). Although rabbit superior cervical ganglion cell bodies have about $1 \frac{1}{2}$ times the surface area of the homologous neurons in the mouse, there are approximately 5 times as many somatic synapses on mouse neurons as on rabbit neurons. Thus, there is a decrease in both the overall number of synapses per cell soma and the number of synapses per unit length of somatic membrane as a function of increasingly complex geometries and increased preganglionic convergence.

Synapses on ganglion cell dendrites. In contrast to the decreased density of somatic innervation as neuronal complexity and convergence increase, the number of synapses per unit length of dendritic membrane was similar for superior cervical ganglion cells among

TABLE |

Density and distribution of synapses within the superior cervical ganglion of five mammals

\begin{tabular}{lccc}
\hline Species $^{a}$ & Synapses $/ 1000 \mu \mathrm{m}^{2 b}$ & $\begin{array}{c}\text { Percentage of } \\
\text { Total Synapses } \\
\text { on Cell Budies }\end{array}$ & $\begin{array}{c}\text { Percentage of } \\
\text { Total Synapses } \\
\text { on Dendrites }\end{array}$ \\
\hline Mouse & 2.9 & 8.5 & 91.5 \\
Hamster & 1.8 & 7.2 & 92.8 \\
Rat & 2.5 & 3.3 & 96.7 \\
Guinea pig & 2.8 & 1.9 & 97.1 \\
Rabbit & 2.1 & 0.8 & 99.2 \\
\hline
\end{tabular}

${ }^{a}$ Animals are ordered according to body size (and according to increasing dendritic complexity of superior cervical ganglion cells; Purves and Lichtman, 1985).

${ }^{b}$ The number of synapses in approximately $130,000 \mu \mathrm{m}^{2}$ of the ganglion was counted for each species. the five species examined and was greater than the density of somatic innervation in all cases (Fig. 3, cf. Fig. 2A).

Since there is no reliable way to assess the total dendritic surface area of a ganglion cell at the ultrastructural level, the actual number of synapses on dendrites cannot be estimated in the same way as the number of synapses on cell bodies. However, the total number of dendritic synapses on a typical cell of each species can be calculated from the number of cell body synapses (Table II) and the percentage of total synapses on dendrites and cell bodies (Table I). According to this calculation, there are about 264 synapses on the dendrites of a mouse superior cervical ganglion cell and about 620 synapses on the dendritic arbor of a typical rabbit cell (Table III). Estimates of the total number of synapses per neuron (Table III) can be obtained by adding the numbers on the cell body and dendrites. The number of synapses on a typical rat superior cervical ganglion cell (the only species in which previous estimates have been made) is 330 (Table III). This number is somewhat greater than values calculated by estimating the total numbers of cells and synapses in the rat supcrior cervical ganglion (244, Östberg et al., 1976; 112, Smolen, 1983).

\section{Discussion}

Distribution of synapses on autonomic ganglion cells. In the present study 1 have shown that the distribution of synapses on superior cervical ganglion cells varies in a systematic way among small mammals. As the complexity of the dendritic arbor increases, and as more inputs converge onto these neurons, fewer synapses are found on the cell body. The density of dendritic innervation, however, is similar regardless of dendritic complexity and convergence and, in fact, is severalfold greater than the density of cell body innervation (cf. Figs. 2 and 3). These observations imply two fundamental points about the innervation of ganglion cells: (1) dendrites provide a preferred site for synapses compared to cell somata, and (2) the decreased innervation of somata as ganglion cell complexity and convergence increase does not reflect a general decrease in the ability of these cells to support synapses.

This relationship between ganglion cell geometry, preganglionic convergence, and the density of somatic innervation in the autonomic nervous system may be a general one. For example, Hume and Purves (1983) found that parasympathetic ciliary ganglion cells of the rabbit receive different degrces of somatic innervation as a function of the number of inputs they receive: ganglion cells with three or more preganglionic inputs have only about half as many somatic contacts as ganglion cells with only one or two inputs. Furthermore, Lichtman (1977) showed that rat submandibular ganglion cells, which generally lack dendrites, receive an average of 44 synaptic boutons on their cell bodies, usually from a single preganglionic input. In contrast, superior cervical ganglion cells in the same species, which are geometrically complex and are innervated by several preganglionic axons, receive only about 11 somatic synapses (see above).

Relationship of cell size to somatic innervation. The number of synapses contacting geometrically simple neurons within a given ganglion has been shown to increase as a function of cell body size in at least some circumstances. Thus, a constant fraction (about $2 \%$ ) of the surface of frog cardiac ganglion cells is covered by synaptic boutons (Sargent, 1983). These neurons do not have dendrites and receive most of their innervation from a single preganglionic axon (Sargent, 1983; see also McMahan and Kuffler, 1971). This observation is interesting in the present context because rabbit and guinea pig superior cervical ganglion cell somata are significantly larger than those of mouse, hamster, or rat (Table II). Thus, rabbit superior cervical ganglion cells have about $50 \%$ more somatic surface area than mouse superior cervical cells; however, they receive only about a fifth as many somatic synapses (Table II). Although the density of cell body innervation on neurons of different sizes within a single superior cervical ganglion is not known, the 


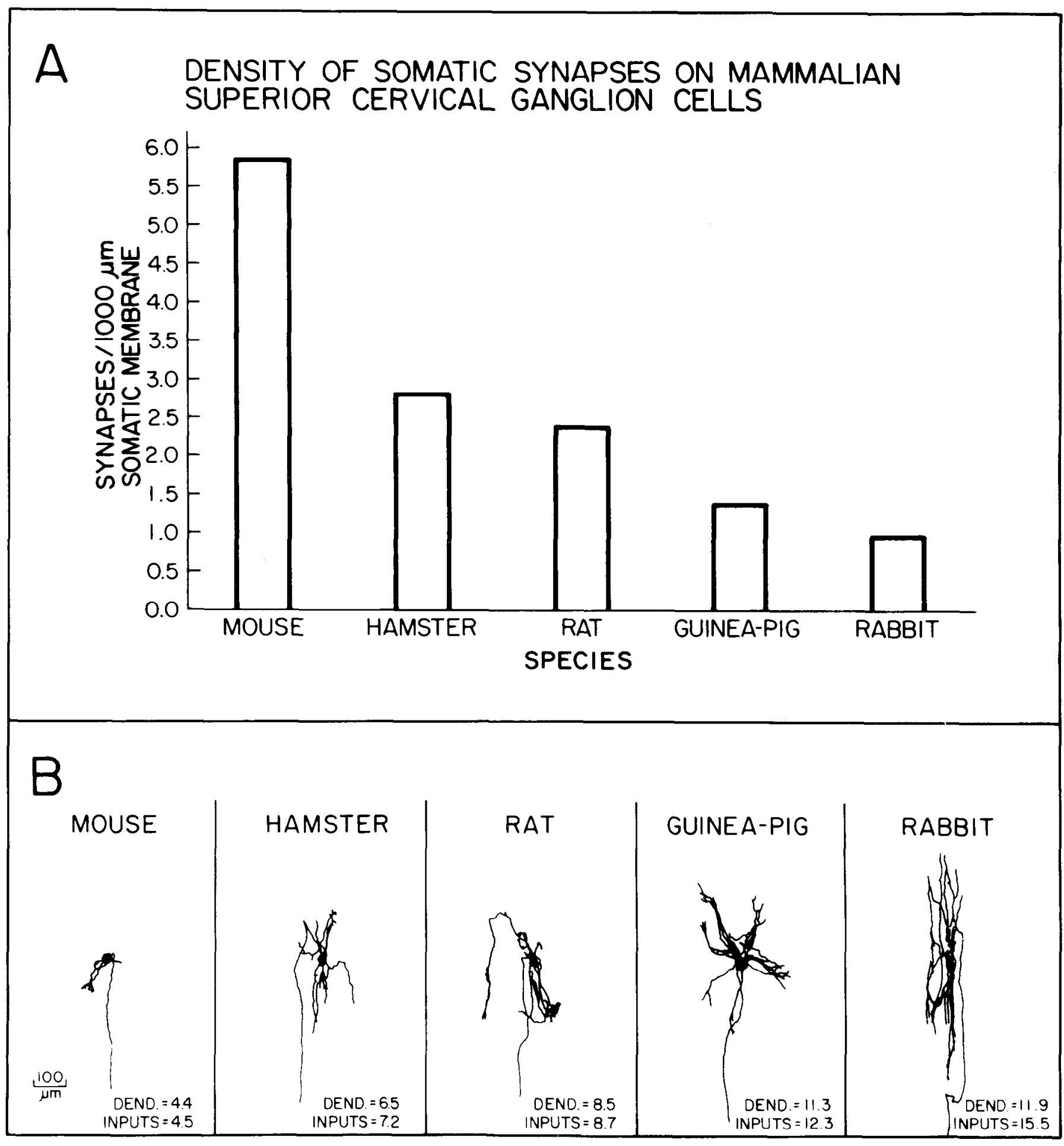

Figure 2. Relationship of the density of somatic innervation to superior cervical ganglion cell complexity and to the number of preganglionic inputs in five marnmals. A, The density of somatic innervation decreases from mouse to rabbit. (Synapses were counted on at least 550 somata in each species.) $B$, Camera lucida drawings of typical superior cervical ganglion cells from each species; the numbers beside the axon of each neuron indicate the average number of primary dendrites (DEND.) in that species and the average number of preganglionic axons (INPUTS) that converge on them (after Purves and Lichtman, 1985). The systematic decrease in density of somatic innervation is inversely related to both the geometrical complexity of ganglion cells and the degree of preganglionic convergence.

idea of a constant density of cell body innervation does not hold for more complex, multiply innervated autonomic cells. Since larger superior cervical ganglion cells have fewer somatic synapses than smaller ones, any mechanism for maintaining a constant density of cell body innervation is apparently over-ridden by some other influence in geometrically complex neurons.

Neuronal competition and decreasing somatic innervation on complex ganglion cells. A variety of studies have indicated that competitive interactions influence the final number of preganglionic inputs that converge on autonomic ganglion cells (Lichtman, 1977; Purves and Lichtman, 1980; Hume and Purves, 1981; Purves, 1983). One factor that determines the outcome of these interactions is the shape of the target neurons: in general, the number of preganglionic inputs an adult ganglion cell receives is linked to the number and 
TABLE ॥

Size of superior cervical ganglion cell somata and the mean number of cell body synapses in five mammals

\begin{tabular}{lcc}
\hline Species & $\begin{array}{c}\text { Mean Surface Area of } \\
\text { Ganglion Cell } \\
\text { Somata }\left(\mu \mathrm{m}^{2}\right)^{\mathrm{a}, b}\end{array}$ & $\begin{array}{c}\text { Mean Number of } \\
\text { Somatic Synapses/ } \\
\text { Ganglion Cell }^{c}\end{array}$ \\
\hline Mouse & 1593 & 24 \\
Hamster & 1833 & 12 \\
Rat & 1752 & 11 \\
Guinea Pig & 2451 & 7 \\
Rabbit & 2485 & 5 \\
\hline
\end{tabular}

${ }^{a}$ Ganglion cell surface area was computed by obtaining the major and minor radii from the cell circumference measurements in the horizontal and transverse planes, respectively, and using the formula for surface area of a prolate ellipsoid.

${ }^{b}$ Guinea pig and rabbit superior cervical ganglion cells, in addition to being larger than those of the other species, often contained two nuclei. In horizontal thin sections $59 \%$ of nucleated cell profiles in the rabbit and $40 \%$ in the guinea pig were binucleate. Binucleate cells were only rarely observed in the rat $(<0.1 \%)$ and hamster $(<0.01 \%)$ and were never seen in the mouse superior cervical gangion. $n \cong 400$ nucleated cell profiles for each species.

${ }^{c}$ The total number of synapses per cell soma was estimated by squaring the average length of synaptic membrane in each species, dividing the mean cell surface area by that number, and multiplying by the percentage of somatic membrane covered by synaptic membrane.

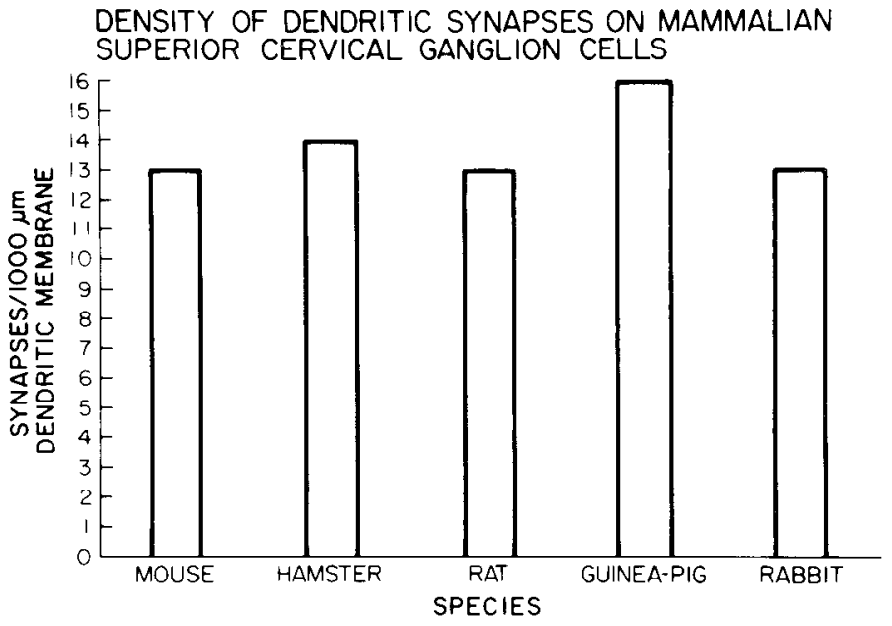

Figure 3. Comparison of the density of dendritic innervation in the superior cervical ganglion of the five species examined. In contrast to the density of somatic innervation, the density of dendritic innervation is similar from animal to animal and is greater than the density of somatic innervation (cf. Fig. 2A). (Synapses were counted for approximately $4000 \mu \mathrm{m}$ of dendritic membrane in each species.)

TABLE III

Estimated number of synapses on ganglion cells in the superior cervical ganglion of five mammals

Number of

Synapses Synapses on Ganglion Cell ${ }^{b}$ Ganglion Cell

\begin{tabular}{lll}
\hline Mouse & 264 & 288 \\
Hamster & 156 & 168 \\
Rat & 319 & 330 \\
Guinea pig & 357 & 364 \\
Rabbit & 620 & 625 \\
\hline
\end{tabular}

${ }^{a}$ Obtained by multiplying the number of synapses on the cell body (from Table II) by the ratio of the percentage of total synapses on dendrites to the percentage of total synapses on somata (from Table I).

${ }^{b}$ Cell body and dendrites. complexity of its dendrites (Purves and Hume, 1981; Purves and Lichtman, 1985). Competition between axons innervating a cell with no dendrites generally results in a single dominant input in maturity; in contrast, competition on cells with dendrites is mitigated so that an increasing number of inputs is retained on increasingly complex cells (Hume and Purves, 1981, 1983; Forehand and Purves, 1984). The results of the present study show that the distribution of synapses on target neurons is also influenced by the presence of dendrites.

Ganglion cells are innervated before they elaborate dendrites; therefore, most initial synapses are somatic (Rubin, 1985). As dendrites develop, an increasing percentage of synapses is found on dendrites (Smolen and Raisman, 1980; Rubin, 1985). For example, although $90 \%$ of synapses in the rat superior cervical ganglion are made in the first postnatal month (Smolen and Raisman, 1980), few, if any, somatic synapses are made during this time (see Rubin, 1985). One reason that more synapses are made on dendrites than on somata is that the total dendritic length increases severalfold in early postnalal lile, whereas the cell body surface area only doubles (Smolen and Beaston-Wimmer, 1984; J. Voyvodic, personal communication). This rapid increase of dendritic compared to somatic surface area, however, does not explain the decreased density of cell body innervation in different animals as a function of increasingly complex geometry and convergence. Thus, whereas the number of inputs that converge on a ganglion cell increases in proportion to the number of dendrites, the ability of these inputs to elaborate synapses on the cell soma decreases. One possible explanation is that this result reflects activity-mediated competitive interactions between the different inputs to the somata of geometrically complex cells (see, e.g., Purves, 1983). Since the cell body is the final common pathway for all ganglion cell activity, asynchronous activity generated by the several different inputs to more complex ganglion cells may limit the ability of synapses from different axons to coexist on the cell body surface. Conversely, synapse formation on dendrites might be less affected by increased convergence because dendrites are innervated by only a subset of the inputs to a particular ganglion cell (Forehand and Purves, 1984) and are to some extent isolated from each other by the passive electrical properties of the dendritic arbor.

\section{References}

Forehand, C. J., and D. Purves (1984) Regional innervation of rabbit ciliary ganglion cells by the terminals of preganglionic axons. J. Neurosci. 4: 112.

Hume, R. I., and D. Purves (1981) Geometry of neonatal neurones and the regulation of synapse elimination. Nature 293: 469-471.

Hume, R. I., and D. Purves (1983) Apportionment of the terminals from single preganglionic axons to target neurons in the rabbit ciliary ganglion. J. Physiol. (Lond.) 338: 259-275.

Lichtman, J. W. (1977) The reorganization of synaptic connexions in the rat submandibular ganglion during post-natal development. J. Physiol. (Lond.) 273: $155-177$.

Matthews, M. R. (1974) Ultrastructure of ganglionic junctions. In The Peripheral Nervous System, J. I. Hubbard, ed., pp. 111-150, Plenum Press, New York.

Matthews, M. R. (1983) The ultrastructure of junctions in sympathetic ganglia of mammals. In Autonomic Ganglia, L. -G. Elfvin, ed., pp. 27-65, John Wiley \& Sons, Chicester.

McMahan, U. J., and S. W. Kuffler (1971) Visual identification of synaptic boutons on living ganglion cells and of varicosities in postganglionic axons in the heart of the frog. Proc. R. Soc. Lond. (Biol.) 177: 485-508.

Östberg, A. -J. C., G. Raisman, P. M. Field, L. L. Iverson, and R. E. Zigmond (1976) A quantitative comparison of the formation of synapses in the rat superior cervical sympathetic ganglion by its own and foreign nerve fibres. Brain Res. 107: 445-470.

Purves, D. (1983) Modulation of neuronal competition by postsynaptic geometry in autonomic ganglia. Trends Neurosci. 6: 1-6.

Purves, D., and R. I. Hume (1981) The relation of postsynaptic geometry to the number of presynaptic axons that innervate autonomic ganglion cells. J. Neurosci. 1: 441-452.

Purves, D., and J. W. Lichtman (1980) The elimination of some synaptic 
connections in autonomic ganglia during early postnatal life. In Ontogenesis and Functional Mechanisms of Peripheral Synapses. INSERM Symposium No. 13, J. Taxi, ed., pp. 15-26, Elsevier/North Holland Biomedical Press, Amsterdam.

Purves, D., and J. W. Lichtman (1985) Geometrical differences among homologous neurons in mammals. Science 228: 298-302.

Purves, D., C. J. Forehand, and J. W. Lichtman (1984) Synaptic distribution on superior cervical ganglion cell somata and dendrites in different mammalian species. Soc. Neurosci. Abstr. 10: 1082

Rubin, E. (1985) Development of the rat superior cervical ganglion: Initial stages of synapse formation. J. Neurosci. 5: 697-704.

Sargent, P. B. (1983) The number of synaptic boutons terminating on Xenopus cardiac ganglion cells is directly correlated with cell size. J. Physiol. (Lond.) 343: 85-104.

Smolen, A. (1983) Retrograde transneuronal regulation of the afferent inner- vation to the rat superior cenvical sympathetic ganglion. J. Neurocytol. 12; $27-45$.

Smolen, A., and P. Beaston-Wimmer (1984) Dendritic development in the rat superior cervical ganglion. Soc. Neurosci. Abstr. 10: 767.

Smolen, A., and G. Raisman (1980) Synapse formation in the rat superior cervical ganglion during normal development and after neonatal deafferentation. Brain Res. 181: 315-323.

Szentágothai, J. (1964) The structure of the autonomic interneuronal synapse. Acta Neurovegetativa 26: 338-359.

Yokota, R., and G. Burnstock (1983) Synaptic organisation of the pelvic ganglion in the guinea-pig. Cell Tissue Res. 232: 379-397.

Yokota, R., and A. Yamauchi (1974) Ultrastructure of the mouse superior cervical ganglion, with particular reference to the pre- and postganglionic elements covering the soma of its principal neurons. Am. J. Anat. 140: 281-298. 